\section{Carrying the Islamic torch}

\section{Ziauddin Sardar}

Arabic Sciences and Philosophy. Editors Basim Musallem, Roshdi Rashed, Jean Jolivet, Muhsin Mahdi and George Saliba. Cambridge University Press. 2/yr. £48, $\$ 75$ (institutional); $£ 28, \$ 39$ (personal); $£ 22$ (members). THE embryonic community of historians
of Arabic and Islamic science and philosophy have been inadequately served by learned journals. Professionals in the field have tended to publish isolated articles either in established international journals of history of science such as

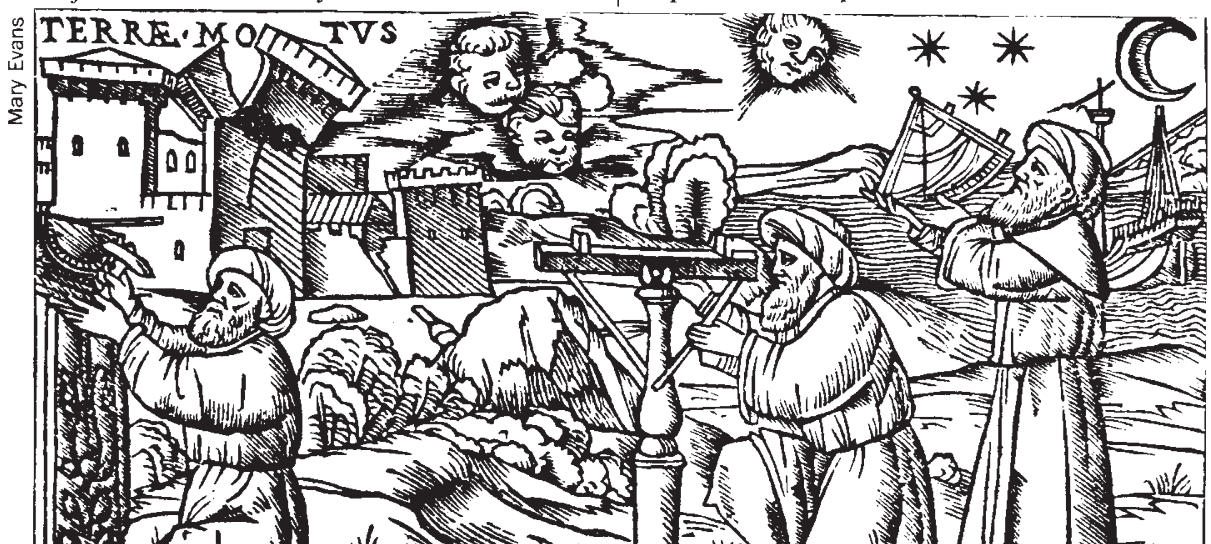

Star-gazers: Arab astronomers (1513)

Isis, History of Science and Archives Internationales d'History des Sciences or national journals such as The British Journal for the History of Science and Indian Journal of the History of Science. Other outlets have included Islamic Culture published from Hyderabad, India, and the Pakistani journal Hamdard Islamicus - but these journals have too broad a canvas and have tended to be low on quality and high on selfcongratulatory prose.

With the arrival, in the mid-1970s, of the Journal for the History of Arabic Science (JHAS), published by the Institute for the History of Ararabic Science of the University of Aleppo, the situation improved dramatically. Here at last was a journal that catered specifically for the professional historians of Islamic science. But JHAS lasted less than a decade: it died not so much from lack of contributions or demand but from political interference.

Some of the more noted historians involved in $J H A S$ are now carrying the torch forward with Arabic Sciences and Philosophy. Launched following the establishment of the International Society for the History of Arabic Sciences and Philosophy in Paris, November 1989, the journal aims to 'crystallize' the 'tentative movement' behind the new disciplines. Covering the period from the eighth to the eighteenth centuries, it intends to "treat the history of Arabic science and the history of Arabic philosophy as part

of the history of science and philosophy in general", paying "special attention to the history of scientific institutions, teaching systems and ideologies which made possible the emergence and development of the scientific and philosophical enterprise in medieval Islam".
Afro-Nature

\section{Walter Gratzer}

Discovery and Innovation. Editor T. T. Isoun. Academy Science Publishers, PO Box 14798, Nairobi, Kenya. 4/yr. Kenya Kshs 975, rest of Africa $\$ 70$, elsewhere $\$ 90$ (institutional); Kenya Kshs 700 , rest of Africa $\$ 38$, elsewhere $\$ 70$ (personal).

IN Yugoslavia, it seems, there are five biochemical societies, and they hold no joint meetings. Such unhappy Balkanization of the scientific estate is what the founders of this Afro-Nature hope presumably to nip in the bud. Their attempt to widen the African scientific and technological community does not go so far as to include South Africa, but the constituency, even so, is far from small. According to the editor, Professor Isoun, Nigeria in 1957 had one University (Ibadan) with 1,000 students. The population of Zaïre counted fewer than 10 graduates among its number. By 1989, when Discovery and Innovation was launched, Nigeria had 30 Universities with 150,000 students and Zaïre had accumulated 30,000 graduates. How many of these are scientists and how many lawyers is not revealed, but even so the momentum of scientific advance in black Africa must be considerable.

What need is there then, Professor
As such it casts a wide net seeking articles on Greek, Indian, Chinese, Latin, Byzantine, Syriac and Hebrew science and philosophy with a bearing on Arabic science and philosophy. The first two issues of Arabic Sciences and Philosophy carry articles in English and French, but the journal will also accept articles in Arabic; however, considering the readership of the journal, English is bound to become its dominant language.

Given the acute needs of its constituency, its wide but well-defined scope, as well as the professional reputations of those involved, Arabic Science and Philosophy is set to become the quality journal in the field. The only point against the journal, which incidentally many will also see as its basic strength, is that it appears to be the sole concern of scholars working in Western institutions: there is no one, either on the editorial board or on the advisory board, from outside Europe and North America. In this respect, too, Arabic Sciences and Philosophy needs to cast its net a little bit wider and bring in those isolated scholars working in the Middle East and elsewhere in the Muslim world.

Ziauddin Sardar is at 1 Orchard Gate, London NW9 GHE, UK.

Isoun asks, for a multidisciplinary journal, given the already abundant number of specialized journals in Africa, many of them now moribund? The answer must surely be that the practice of science now so transcends frontiers that the role of parochial journals is shrinking and research that is fit for print is migrating increasingly into supranational publications.

Discovery and Innovation is sponsored by the Africal Academy of Sciences, which is an offshoot of the Third World Academy of Sciences, based in Trieste. It is handsomely designed and produced, and contains a mixture of news, reviews and original papers, somewhat dominated by Kenya and Nigeria. Abstracts are in English and French. The topics are a mix of basic and applied. A review of biotechnology in the control of parasitic diseases that could have sprung from the pages of an American journal nestles beside dissertations on 'Production of non-fermented beverage from ripe bananas' and 'Effect of source of yeast on alcohol content and quality of pineapple wine'. The depredations of the cassave mealy bug Phenacoccus manihoti are juxtaposed with 'Boson critical selfmixing and the $\lambda$-transition in ${ }^{4} \mathrm{He}$ ' from Malawi and 'Approximation of fixed points of Lipshitz pseudo-contractive mappings in Banach spaces' from the University of Nigeria.

The journal will yield copious pickings for journalists, whether they are after 